\title{
Pemilihan Kindergarten Teacher Menggunakan Metode Weight Aggregated Sum Product Assesment (WASPAS)
}

\author{
Vivi Anggriani*, Purwadi**, Ardianto Pranata*** \\ * Sistem Informasi, STMIK Triguna Dharma, Medan \\ ** Manajemen Informatika, STMIK Triguna Dharma, Medan \\ *** Sistem Komputer, STMIK Triguna Dharma, Medan
}

\begin{tabular}{|c|c|}
\hline Article Info & ABSTRACT \\
\hline Article history: & Raudhatul Athfal (RA) merupakan salah satu lembaga pendidikan islam anak \\
\hline Received Jan $02^{\text {th }}, 2022$ & usia dini yang tumbuh dan berkembang di indonesia. Maka dari itu Raudhatul \\
\hline Revised Jan $15^{\text {th }}, 2022$ & Athfal membutuhkan seorang tenaga pengajar atau kindergarten teacher guna \\
\hline Accepted Jan $27^{\text {th }}, 2022$ & $\begin{array}{l}\text { membantu mengunggah potensi anak didik agar dapat tumbuh dan berkembang } \\
\text { dimasa pertumbuhannya. Kemudian untuk menentukan kindergarten teacher } \\
\text { yang tepat maka harus dilakukan penilaian kelayakan dengan menimbang }\end{array}$ \\
\hline Keyword: & berbagai kriteria, agar tidak berdampak buruk pada RA Umar Mirza. Oleh \\
\hline Kindergarten Teacher & karena itu diperlukan sebuah Sistem Pendukung Keputusan yang dapat \\
\hline Kriteria & membantu untuk menentukan kindergarten teacher \\
\hline Raudhatul Athfal & $\begin{array}{l}\text { ASPAS. Hasil dari dari pen } \\
\text { Sistem Pendukung Kepu }\end{array}$ \\
\hline Sistem Pendukung Keputusan & metode WASPAS dapat dijadikan solusi yang tepat dalam membantu pihak RA \\
\hline WASPAS & $\begin{array}{l}\text { Umar Mirza di dalam menentukan kindergarten teacher mana yang layak sesuai } \\
\text { dengan kriteria yang diharapkan. }\end{array}$ \\
\hline
\end{tabular}

\author{
Corresponding Author:* \\ Nama: Vivi Anggriani \\ Program Studi: Sistem Informasi \\ Afiliasi: STMIK Triguna Dharma \\ Email: vivianggriani0312@gmail.com
}

\section{PENDAHULUAN}

Raudhatul Athfal (RA) merupakan salah satu lembaga pendidikan islam anak usia dini yang tumbuh dan berkembang di indonesia. Raudhatul Athfal artinya taman, sedangkan Athfal artinya kanak-kanak. Raudhatul Athfal berada dibawah naungan Dapartemen Agama melalui SK mentri agama. Selain materi umum, RA memperkenalkan pula dasar-dasar ajaran agama islam kepada anak didiknya. Raudhatull Athfal setara dengan taman kanak-kanak, dimana kurikulumnya ditekankan pada pemberian rangsangan pembelajaran untuk membantu pertumbuh kembang jasmani serta rohani sehingga anak mempunyai kesiapan dalam memasuki pendidikan lebih lanjut [1].

Kindergarten Teacher merupakan istilah dari Guru Taman Kanak-kanak/ Raudhatul Athfal. Yang dimana Kindergarten Teacher itu sendiri berasal dari bahasa asing. Guru Raudhatul Athfal adalah sebagai pendidik yang dapat menggunggah potensi anak didiknya melalui pendidikan untuk dapat berkembang dan tumbuh dimasa pertumbuhannya. Tugas mendidik anak usia dini tidaklah mudah, sebab anak belajar dari apa yang dilihat, didengar, serta dirasakannya. Pendidik bukan sekedar orang yang menstranfer ilmu ke anakanak, akan tetapi lebih dari itu, merupakan orang yang berperan memberikan konsep ilmu terlebih lagi pada pembentukan perilaku serta sikap anak didik [2].

Dengan demikian, semua pihak perlu memahami pentingnya tumbuh dan kembang anak didik. Karena itu merupakan tahap awal dalam proses pembelajaran. RA Umar Mirza merupakan lembaga pendidikan Islam yang terdiri dari Raudhtal Athfal. Yayasan ini didirikan pada tanggal 19 Februari 2016 dan sudah berhasil mendapatkan Izin dari Dinas Pendidikan Kabupaten Deli Serdang.

Seiring perkembangan zaman banyak calon guru baru Raudhatul Athfal yang membutuhkan lapangan pekerjaan dimana para calon guru baru ingin mengimplementasikan kemampuannya di dalam hal mengajar untuk membentuk dan membina anak didik menjadi pribadi yang mandiri, beriman, berilmu, cerdas, terampil 
dan berprestasi. Maka dari itu beberapa sekolah biasanya memiliki beberapa kriteria untuk menentukan kindergarten teacher yang layak untuk menjadi pengajar. Sama seperti halnya RA Umar Mirza yang dimana dalam menentukan kindergarten teacher memiliki beberapa syarat kriteria yang telah ditetapkan oleh pihak sekolah. Hal ini penting dilakukan, karena jika tanpa ada suatu kriteria dalam menentukan kindergarten teacher akan lebih cenderung kurang maksimal dalam hal mengajar.

Sistem Pendukung Keputusan (SPK) adalah aplikasi interaktif berbasis komputer yang menggabungkan antara data serta model matematis untuk membantu proses pengambilan keputusan dalam menanggulangi suatu permasalahan [3]. Sistem Pendukung Keputusan digunakan untuk membantu pengambilan keputusan dalam situasi semiterstruktur serta situasi tidak terstruktur yang mana tidak seorang pun tahu secara pasti bagaimana keputusan seharusnya dibuat [4]. Sistem yang dibangun cocok untuk menangani mekanisme sistem pendukung keputusan penerima BPNT sesuai kriteria [5].

SPK digunakan dalam penerimaan dana BOS jenjang SMA sebagai rekomendasi mana sekolah yang berhak menerima dana BOS [6]. SPK yang dapat membantu untuk menentukan kelayakan penerimaan bantuan siswa miskin dengan cepat dan tepat [7]. SPK digunakan untuk menentukan tingkat kepuasan pelanggan terhadap pelayanan di toko Indomaret [8], Dengan menggunakan SPK maka dapat menentukan lokasi pembangunan perumahan type $36 \mathrm{~m} / \mathrm{s}$ [9].

Penerapan metode WASPAS telah dilakukan sebelumnya oleh para peneliti, diantaranya untuk menentukan Ketua Kemuslimahan pusat komunikasi daerah lembaga dakwah kampus SUMUT [10]. Menentukan calon penjahit [11]. Menentukan lokasi strategis cabang baru [12]. Hasil dari penelitian adalah sebuah aplikasi sistem pendukung keputusan yang mengadopsi metode WASPAS yang mampu menjawab permasalahan yang ada di Al Haramain Tour dan Travel [13].

Sistem Pendukung Keputusan bertujuan untuk menyediakan informasi dan memberikan prediksi serta pengarahan kepada pihak RA Umar Mirza agar dapat melakukan pengambilan keputusan untuk menentukan kindergarten teacher dengan mengadopsi metode Weight Aggregated Sum Product Assessment (WASPAS). Metode WASPAS merupakan metode yang dapat mengurangi kesalahan-kesalahan atau mengoptimalkan dalam penaksiran untuk pemilihan nilai tertinggi dan terendah.

\section{METODE PENELITIAN}

Metode penelitian merupakan langkah-langkah yang di lakukan untuk mengumpulkan data atau informasi yang dibutuhkan oleh seorang pengembang perangkat lunak (Software) sebagai tahapan serta gambaran penelitian yang akan dibuat.

\subsection{Metode WASPAS}

Metode WASPAS merupakan gabungan unik dari pendekatan MCDM yaitu model jumlah tertimbang (Weight Sum Model/WSM)dan model produk tertimbang (Weight Product Model/WPM). Pada awalnya memerlukan normalisasi linier berasal dari elemen matriks keputusan dengan menggunakan dua persamaan [14]. WASPAS merupakan metode yang menggabungkan 2 kriteria optimalitas, kriteria pertama dari optimalitas adalah penjumlahan tertimbang dari normalisasi nilai kinerja yang mirip dengan metode SAW dan kriteria kedua mirip dengan metode WP [15].

Tahapan metode WASPAS [15], sebagai berikut :

1. Pembentukan Decicion Making Matrix, seperti rumus (1).

$$
x=\left(\begin{array}{ccccc}
x_{i j} & \cdots & x_{i j} & \cdots & x_{n j} \\
\vdots & \cdots & \vdots & \cdots & \vdots \\
x_{n 1} & \cdots & x_{m j} & \cdots & x_{m n}
\end{array}\right) i=m, 0 ; j=1, n
$$

2. Penormalisasian Decision Making Matrix, seperti rumus (2) dan (3).

Kiteria Benefit

$X_{i j}=\frac{X_{i j}}{\max X_{i j j}}$

Kriteria Cost

$X_{i j}=\frac{\min X_{i j}}{x_{i j}}$

J-SISKO TECH Vol. 5, No. 1, Januari 2022 : 55-65 
3. Matrik keputusan ternormalisasi, seperti rumus (4).

$$
x=\left(\begin{array}{ccccc}
x_{i j} & \cdots & x_{i j} & \cdots & x_{n j} \\
\vdots & \cdots & \vdots & \cdots & \vdots \\
x_{n 1} & \ldots & x_{m i} & \cdots & x_{m n}
\end{array}\right) i=\bar{m}, 0 ; j=1, \bar{n}
$$

4. Menentukan bobot matriks yang sudah dinormalisasi, seperti rumus (5).

$$
\sum_{j=1}^{n} w_{j}=1
$$

5. Menentukan nilai Qi, seperti rumus (6).

$$
Q_{i}=0,5 \sum_{j=1}^{n} x_{i j}+0,5 \prod_{j=1}^{n}\left(x_{i j}^{w j}\right)
$$

\subsection{Data Kriteria}

Berikut tabel 1 merupakan data kriteria yang didapatkan dalam penyelesaian masalah terkait penentuan Kindergarten Teacher Pada RA Umar Mirza:

Tabel 1. Bobot Keterangan Kriteria

\begin{tabular}{ccccc}
\hline No & $\begin{array}{c}\text { Kode } \\
\text { Kriteria }\end{array}$ & Nama Kriteria & $\begin{array}{c}\text { Bobot } \\
(\boldsymbol{\%})\end{array}$ & Jenis \\
\hline 1 & C1 & Pendidikan & 0,30 & Benefit \\
2 & C2 & Jurusan & 0,20 & Benefit \\
3 & C3 & Umur & 0,10 & Cost \\
4 & C4 & Kemampuan Penyampaian Materi & 0,25 & Benefit \\
5 & C5 & Kemampuan Psikis & 0,15 & Benefit \\
\hline
\end{tabular}

Skala bobot yang diberikan untuk setiap kriteria pada penentuan kindergarten teacher ini ditunjukan pada tabel 2 s/d tabel 6 dibawah ini:

Tabel 2. Bobot Kriteria Pendidikan

\begin{tabular}{ccc}
\hline No & Pendidikan & Bobot \\
\hline 1 & S1 & 3 \\
2 & D3 & 2 \\
3 & SMA & 1 \\
\hline
\end{tabular}

Tabel 3. Bobot Kriteria Jurusan

\begin{tabular}{ccc}
\hline No & Jurusan & Bobot \\
\hline 1 & PAUD & 4 \\
2 & Pendidikan Bahasa Arab & 3 \\
3 & Strata Lain & 2 \\
4 & IPA/IPS & 1 \\
\hline & & Tabel 4. Bobot Kriteria Umur \\
\hline No & Bobot \\
\hline 1 & Umur & 3 \\
2 & $20-25$ & 2 \\
3 & $26-30$ & 1 \\
\hline
\end{tabular}


Tabel 5. Bobot Kriteria Kemampuan Penyampaian Materi

\begin{tabular}{ccc}
\hline No & $\begin{array}{c}\text { Kemampuan } \\
\text { Penyampaian Materi }\end{array}$ & Bobot \\
\hline 1 & Sangat Baik & 5 \\
2 & Baik & 4 \\
3 & Cukup & 3 \\
4 & Kurang Baik & 2 \\
5 & Buruk & 1 \\
\hline
\end{tabular}

Tabel 6. Bobot Kriteria Kemampuan Psikis

\begin{tabular}{ccc}
\hline No & Umur & Bobot \\
\hline 1 & Sangat Baik & 3 \\
2 & Baik & 2 \\
3 & Kurang Baik & 1 \\
\hline
\end{tabular}

\subsection{Data Alternatif}

Berikut tabel 7 merupakan data alternatif yang didapatkan dalam penyelesaian masalah terkait penentuan Kindergarten Teacher Pada RA Umar Mirza:

Tabel 7. Data Primer Kindergarten Teacher

\begin{tabular}{|c|c|c|c|c|c|c|}
\hline $\begin{array}{l}\text { Kode } \\
\text { Alternatif }\end{array}$ & Nama & Pendidikan & Jurusan & Umur & $\begin{array}{c}\text { Kemampuan } \\
\text { Penyampaian } \\
\text { Materi } \\
\end{array}$ & $\begin{array}{c}\text { Kemampuan } \\
\text { Psikis }\end{array}$ \\
\hline A01 & $\begin{array}{c}\text { Zulkarnaen, } \\
\text { Sag }\end{array}$ & S1 & $\begin{array}{l}\text { Hukum } \\
\text { Perdana } \\
\text { Islam }\end{array}$ & 47 & Sangat Baik & Baik \\
\hline A02 & $\begin{array}{c}\text { Endah Sapto } \\
\text { Rini, S.pd }\end{array}$ & S1 & PIAUD & 22 & Sangat Baik & Sangat Baik \\
\hline A03 & $\begin{array}{c}\text { Raja } \\
\text { Nurhafni, } \\
\text { S.pd }\end{array}$ & S1 & $\begin{array}{l}\text { Pendidikan } \\
\text { Matematika }\end{array}$ & 23 & Sangat Baik & Baik \\
\hline A04 & $\begin{array}{c}\text { Zuyina } \\
\text { Mahfuza } \\
\text { Berutu, S.pd }\end{array}$ & S1 & $\begin{array}{c}\text { Pendidikan } \\
\text { Bahasa Arab }\end{array}$ & 23 & Sangat Baik & Sangat Baik \\
\hline A05 & $\begin{array}{c}\text { Dinda } \\
\text { Umaya, S.pd }\end{array}$ & S1 & $\begin{array}{c}\text { Pendidikan } \\
\text { Bahasa } \\
\text { Indonesia }\end{array}$ & 22 & Baik & Baik \\
\hline A06 & $\begin{array}{c}\text { Dinda } \\
\text { Annisa } \\
\text { Ramadhani, } \\
\text { S.pd }\end{array}$ & S1 & PIAUD & 22 & Sangat Baik & Sangat Baik \\
\hline A07 & $\begin{array}{l}\text { R1zky } \\
\text { Salsabila } \\
\text { Putri }\end{array}$ & SMA & PIAUD & 20 & Baik & Baik \\
\hline A08 & Zuriarty & SMA & IPA & 52 & Baik & Baik \\
\hline A09 & $\begin{array}{l}\text { Khairi } \\
\text { Fadilah, } \\
\text { S.sos }\end{array}$ & S1 & $\begin{array}{c}\text { Bimbingan } \\
\text { Penyuluhan } \\
\text { Islam }\end{array}$ & 22 & Baik & Baik \\
\hline
\end{tabular}




\section{ANALISA DAN HASIL}

\subsection{Penerapan Metode WASPAS}

Algoritma penyelesaian dari metode Weighted Aggregated Sum Product Assesment (WASPAS), dapat dilihat di bawah ini.

1. Membuat Matriks Keputusan

Dibawah ini tabel 8 merupakan nilai hasil konversi alternatif.

Tabel 8. Nilai Hasil Konversi Alternatif

\begin{tabular}{lcccccc}
\hline Alt & Nama & C1 & C2 & C3 & C4 & C5 \\
\hline A01 & Zulkarnaen, Sag & 3 & 2 & 1 & 5 & 2 \\
A02 & Endah Sapto Rini, S.pd & 3 & 4 & 3 & 5 & 3 \\
A03 & Raja Nurhafni, S.pd & 3 & 2 & 3 & 5 & 2 \\
A04 & Zuyina Mahfuza Berutu, S.pd & 3 & 3 & 3 & 5 & 3 \\
A05 & Dinda Umaya, S.pd & 3 & 2 & 3 & 4 & 2 \\
A06 & Dinda Annisa Ramadhani, S.pd & 3 & 4 & 3 & 5 & 3 \\
A07 & Rizky Salsabila Putri & 1 & 4 & 3 & 4 & 2 \\
A08 & Zuriarty & 1 & 1 & 1 & 4 & 2 \\
A09 & Khairi Fadilah, S.sos & 3 & 2 & 3 & 4 & 2 \\
\hline
\end{tabular}

Matriks keputusan berdasarkan data hasil konversi nilai alternatif adalah :

$$
X=\left(\begin{array}{l}
32152 \\
34353 \\
32352 \\
33353 \\
32342 \\
34353 \\
14342 \\
11342 \\
32342
\end{array}\right)
$$

2. Melakukan Normalisasi Matriks Keputusan

Berikut ini adalah normalisasi matriks dari nilai alternatif sesuai dengan jenis kriterianya. Normalisasi untuk Kriteria C1 Benefit :
$\mathrm{A}_{11}=\frac{3}{-1}=1$
$\mathrm{A}_{21}=\frac{3}{2}=1$
$\mathrm{A}_{31}=\frac{3}{3}=1$

$$
\begin{aligned}
& \mathrm{A}_{41}=\frac{a}{3}=1 \\
& \mathrm{~A}_{51}=\frac{3}{3}=1 \\
& \mathrm{~A}_{61}=\frac{3}{3}=1
\end{aligned}
$$

Normalisasi untuk Kriteria C2 Benefit :

$\mathrm{A}_{12}=\frac{2}{4}=0,50$

$\mathrm{A}_{22}=\frac{4}{4}=1$

$\mathrm{A}_{32}=\frac{\frac{4}{2}}{4}=0,50$

$$
\begin{aligned}
& \mathrm{A}_{42}=\frac{3}{4}=0,75 \\
& \mathrm{~A}_{52}=\frac{2}{4}=0,50 \\
& \mathrm{~A}_{62}=\frac{4}{4}=1
\end{aligned}
$$

Normalisasi unttuk Kriteria C3 Cost:
$\mathrm{A}_{13}=\frac{1}{1}=1$
$\mathrm{A}_{23}=\frac{1}{\mathrm{a}}=0,33$

$$
\begin{aligned}
& \mathrm{A}_{71}=\frac{1}{3}=0,33 \\
& \mathrm{~A}_{81}=\frac{1}{3}=0,33 \\
& \mathrm{~A}_{91}=\frac{3}{3}=1
\end{aligned}
$$$$
\begin{aligned}
& \mathrm{A}_{72}=\frac{4}{4}=1 \\
& \mathrm{~A}_{82}=\frac{1}{4}=0,25 \\
& \mathrm{~A}_{92}=\frac{\frac{2}{2}}{4}=0,50
\end{aligned}
$$ 


$$
\mathrm{A}_{33}=\frac{1}{\mathrm{a}}=0,33 \quad \mathrm{~A}_{63}=\frac{1}{\mathrm{a}}=0,33 \quad \mathrm{~A}_{93}=\frac{1}{\mathrm{a}}=0,33
$$

Normalisasi unttuk Kriteria C4 Benefit:

$\begin{array}{lll}\mathrm{A}_{14}=\frac{5}{5}=1 & \mathrm{~A}_{44}=\frac{5}{5}=1 & \mathrm{~A}_{74}=\frac{4}{5}=0,80 \\ \mathrm{~A}_{24}=\frac{5}{5}=1 & \mathrm{~A}_{54}=\frac{4}{5}=0,80 & \mathrm{~A}_{84}=\frac{4}{5}=0,80 \\ \mathrm{~A}_{34}=\frac{5}{5}=1 & \mathrm{~A}_{64}=\frac{5}{5}=1 & \mathrm{~A}_{94}=\frac{4}{5}=0,80\end{array}$

Normalisasi unttuk Kriteria C5 Benefit:

$$
\begin{aligned}
& \mathrm{A}_{15}=\frac{2}{3}=0,67 \\
& \mathrm{~A}_{25}=\frac{\frac{3}{3}}{3}=1 \\
& \mathrm{~A}_{35}=\frac{2}{3}=0,67 \\
& \mathrm{~A}_{45}=\frac{3}{3}=1 \\
& \mathrm{~A}_{55}=\frac{2}{3}=0,67 \\
& \mathrm{~A}_{65}=\frac{3}{3}=1
\end{aligned}
$$

$$
\begin{aligned}
& \mathrm{A}_{75}=\frac{2}{3}=0,67 \\
& \mathrm{~A}_{85}=\frac{2}{3}=0,67 \\
& \mathrm{~A}_{95}=\frac{3}{3}=0,67
\end{aligned}
$$

Berikut ini adalah hasil normalisasi matriks keputusan secara keseluruhan yaitu sebagai berikut:

$$
X=\left(\begin{array}{ccccc}
1 & 0,50 & 1 & 1 & 0,67 \\
1 & 1 & 0,33 & 1 & 1 \\
1 & 0,50 & 0,33 & 1 & 0,67 \\
1 & 0,75 & 0,33 & 1 & 1 \\
1 & 0,50 & 0,33 & 0,80 & 0,67 \\
1 & 1 & 0,33 & 1 & 1 \\
0,33 & 1 & 0,33 & 0,80 & 0,67 \\
0,33 & 0,25 & 1 & 0,80 & 0,67 \\
1 & 0,50 & 0,33 & 0,80 & 0,67
\end{array}\right)
$$

3. Menghitung Nilai Rating Tertinggi (Qi)

Perhitunganmya yaitu sebagai berikut:

1. Nilai Alternatif A1 (Q1)

$$
\begin{aligned}
& \mathbf{Q 1}=0,5 \sum(1 * 0,30)+(0,50 * 0,20)+(1 * 0,10)+(1 * 0,25)+(0,67 * 0,15) \\
& +0,5 \prod(1)^{0,30 *(0,50)^{0,20} *(1)^{0,10 *}(1)^{0,25} *(0,67)^{0,15}} \\
& =0,5 \sum(0,30)+(0,10)+(0,10)+(0,25)+(0,10)+0,5 \prod(1) *(0,87) *(1) *(1) *(0,94) \\
& =0,5 \sum(0,85)+0,5 \prod(0,81) \\
& =0,43+0,41=0,84
\end{aligned}
$$

2. Nilai Alternatif A2 (Q2)

$$
\begin{aligned}
& \mathbf{Q 2}=0,5 \sum(1 * 0,30)+(1 * 0,20)+(0,33 * 0,10)+(1 * 0,25)+(1 * 0,15)
\end{aligned}
$$

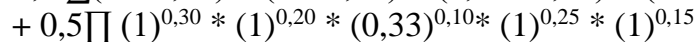

$$
\begin{aligned}
& =0,5 \sum(0,30)+(0,20)+(0,03)+(0,25)+(0,15)+0,5 \prod(1) *(1) *(0,89) *(1) *(1) \\
& =0,5 \sum(0,93)+0,5 \prod(0,89) \\
& =0,46+0,45 \\
& =0,91
\end{aligned}
$$

\section{Nilai Alternatif A3 (Q3)}

$$
\begin{aligned}
& \mathbf{Q 3}=0,5 \sum(1 * 0,30)+(0,50 * 0,20)+(0,33 * 0,10)+(1 * 0,25)+(0,67 * 0,15) \\
& +0,5 \prod(1)^{0,30} *(0,50)^{0,20} *(0,33)^{0,10 *}(1)^{0,25} *(0,67)^{0,15} \\
& =0,5 \sum(0,30)+(0,10)+(0,03)+(0,25)+(0,10)+0,5 \prod(1) *(0,87) *(0,89) *(1) *(0,94) \\
& =0,5 \sum(0,78)+0,5 \prod(0,73)
\end{aligned}
$$


$=0,39+0,37$

$=0,76$

4. Nilai Alternatif A4 (Q4)

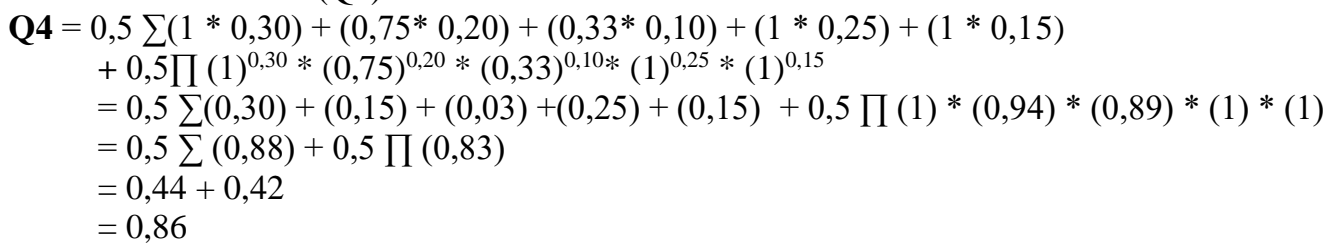

\section{Nilai Alternatif A5 (Q5)}

$$
\begin{aligned}
\text { Q5 }= & 0,5 \sum(1 * 0,30)+(0,50 * 0,20)+(0,33 * 0,10)+(0,80 * 0,25)+(0,67 * 0,15) \\
& +0,5 \prod(1)^{0,30 *(0,50)^{0,20} *(0,33)^{0,10 *}(0,80)^{0,25} *(0,67)^{0,15}}
\end{aligned}
$$

Langkah selanjutnya yaitu menentukan tingkatan peringkat atau kelulusan dari hasil perhitungan metode WASPAS seperti dijelaskan pada tabel 9 dibawah ini.

\begin{tabular}{cc}
\multicolumn{2}{c}{ Tabel 9. Batas Nilai Kelayakan } \\
\hline Kelulusan & Bobot \\
\hline Tidak Lulus & $0-0,75$ \\
Lulus & $>0,76$ \\
\hline
\end{tabular}

Maka dari total hasil perhitungan diatas bisa disimpulkan bahwa alternatif yang layak menjadi kindergarten teacher yaitu alternatif yang memiliki nilai 0,76 atau lebih. Sehingga hasil keputusan tampil pada tabel 10 seperti berikut ini.

Tabel 10. Hasil Keputusan

\begin{tabular}{cccc}
\hline Kode & Nama & Nilai Akhir & Keputusan \\
\hline A02 & Endah Sapto Rini, S.pd & 0,91 & Lulus \\
A06 & $\begin{array}{c}\text { Dinda Annisa Ramadhani, } \\
\text { S.pd }\end{array}$ & 0,91 & Lulus \\
A04 & Zuyina Mahfuza Berutu, S.pd & 0,86 & Lulus \\
A01 & Zulkarnaen, Sag & 0,84 & Lulus \\
A03 & Raja Nurhafni, S.pd & 0,76 & Lulus \\
A05 & Dinda Umaya, S.pd & 0,71 & Tidak Lulus \\
A09 & Khaira Fadillah, S.sos & 0,71 & Tidak Lulus \\
A07 & Rizky Salsabila Putri & 0,60 & Tidak Lulus \\
A08 & Zuriarty & 0,52 & Tidak Lulus \\
\hline
\end{tabular}

Standar nilai minimal yang memperoleh Kindergarten Teacher sesuai dengan ketentuan dari pihak sekolah yaitu diatas 0.76. Akhir dari hasil perhitungan diatas diperoleh nilai A02 (Endah Sapto Rini, S.pd ), A06 (Dinda Annisa Ramadhani, S.pd ), A04 (Zuyina Mahfuza Berutu, S.pd ), A01 (Zulkarnaen, Sag ), A03 (Raja Nurhafni, S.pd ), yang nilainya mencukupi > 0.76 sehingga dinyatakan layak menjadi Kindergarten Teacher. 


\subsection{Implementasi Sistem}

Implementasi sistem merupakan bagian yang menerangkan tentang penerapan dan hasil dari sistem pendukung keputusan menentukan kindergarten teacher pada RA Umar Mirza. Pada implementasi ini akan menampilkan rancangan interface yang telah dibuat. Implementasi sebagai dukungan sistem analisa yaitu sebagai berikut :

1. Tampilan Form Login

Berikut gambar 1 merupakan tampilan dari Form Login yang berfungsi untuk melakukan proses validasi Username dan Password pengguna :

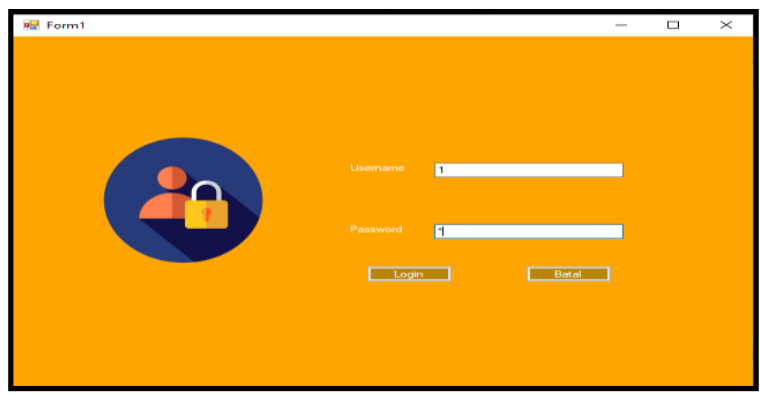

Gambar 1. Tampilan Form Login

2. Tampilan Form Menu Utama

Berikut gambar 2 merupakan tampilan dari Form Menu utama yang berfungsi sebagai halaman utama yang berisi menu navigasi untuk membuka sebuah Form :

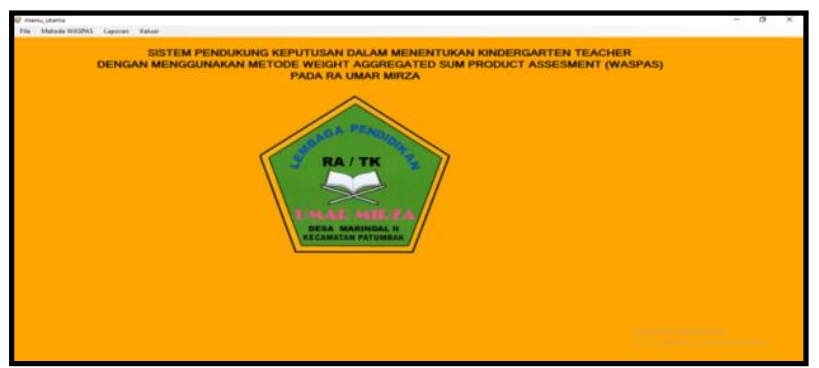

Gambar 2. Tampilan Menu Utama

\section{Tampilan Form Alternatif}

Berikut gambar 3 merupakan tampilan dari Form Alternatif yang berfungsi untuk mengelola data alternatif :

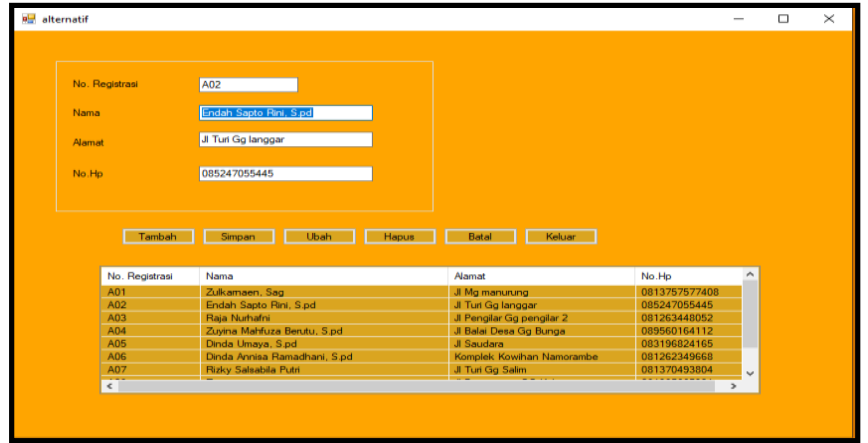

Gambar 3. Tampilan Form Alternatif 


\section{Tampilan Form Data Kriteria}

Berikut gambar 4 merupakan tampilan dari Form Data Kriteria yang berfungsi untuk menampilkan data krteria:

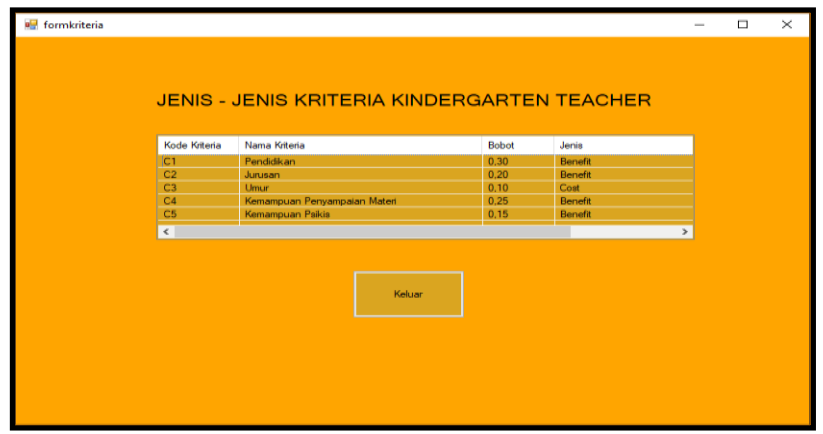

5. Tampilan Form Penilaian

Gambar 4. Tampilan Form Kriteria

Berikut gambar 5 merupakan tampilan dari Form Penilaian yang berfungsi untuk memberi penilaian :

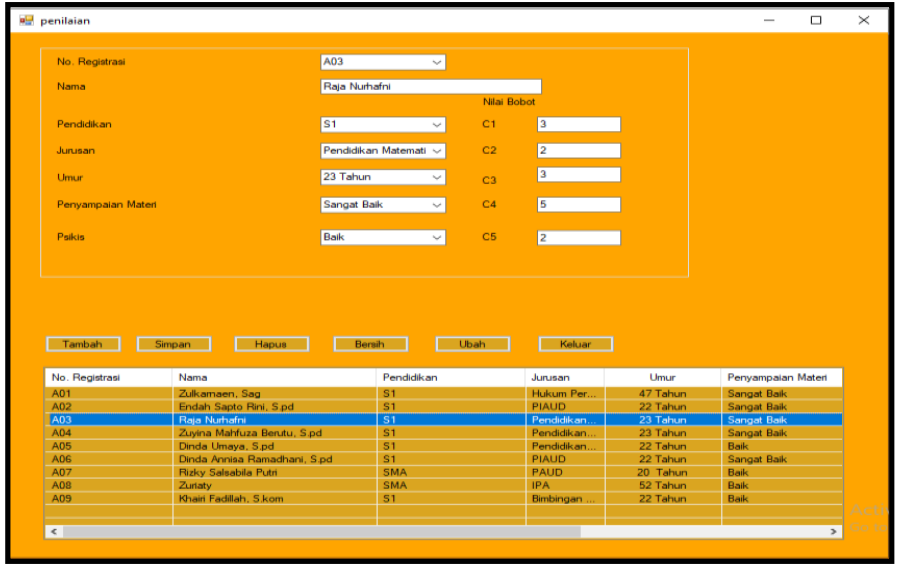

Gambar 5. Tampilan Form Penilaian

\section{Tampilan Form Proses WASPAS}

Berikut gambar 6 merupakan tampilan dari Form Proses WASPAS yang berfungsi untuk melakukan proses perhitungan dengan menggunakan metode Weighted Aggregated Sum Product Assesment (WASPAS).

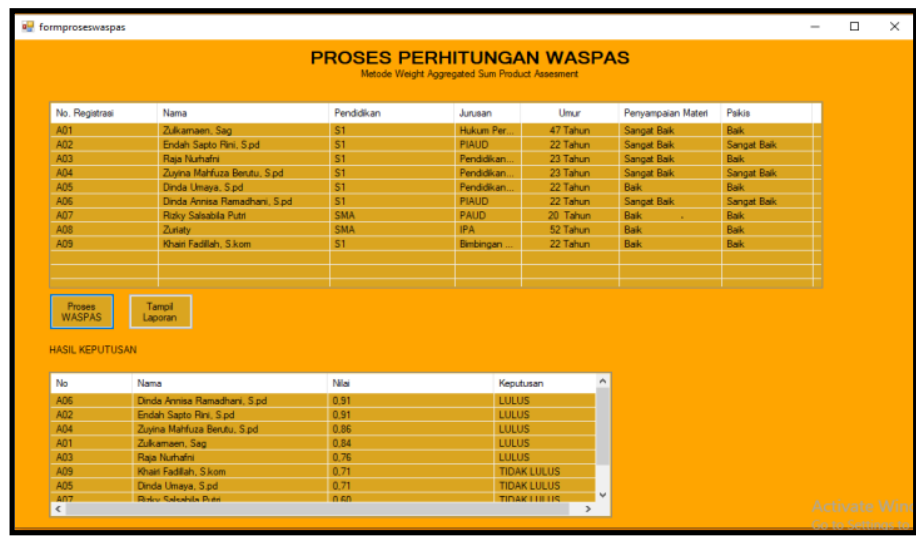

Gambar 6. Tampilan Form Laporan

Pemilihan Kindergarten Teacher Dengan Menggunakan Metode WASPAS (Vivi Anggriani) 
7. Tampilan Form Laporan

Berikut gambar 7 merupakan tampilan dari Form Laporan yang berfungsi untuk melihat laporan dari hasil perhitungan :

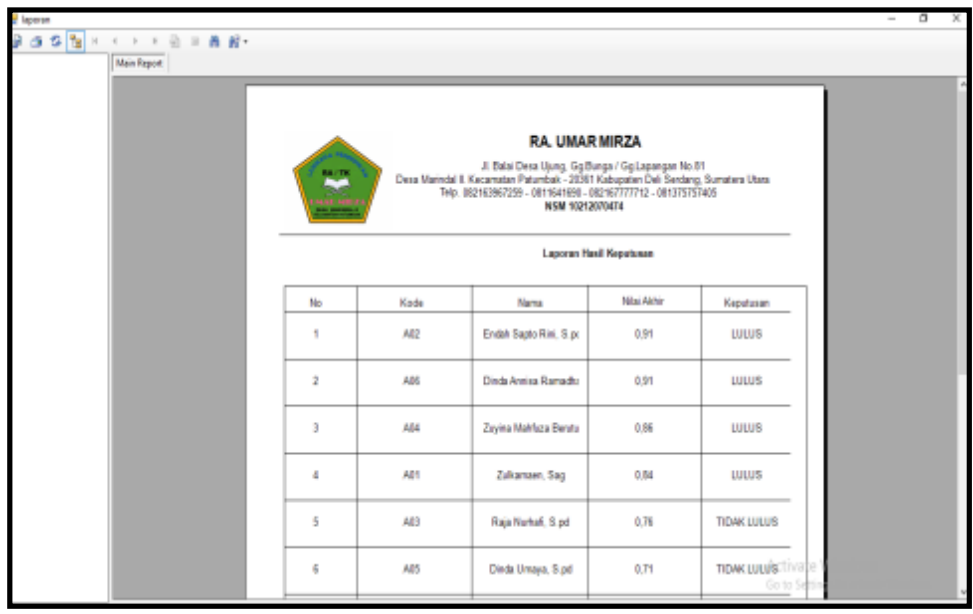

Gambar 7. Tampilan Form Laporan

\section{KESIMPULAN}

Setelah dilakukan penelitian, berdasarkan yang telah dijelaskan pada Pendahuluan maka kesimpulan dari penelitian ini yaitu sebagai berikut:

1. Berdasarkan hasil analisa, metode Weighted Aggreated Sum Product Assesment (WASPAS) dapat diterapkan dalam pemecahan masalah penentuan kindergarten teacher pada RA Umar Mirza.

2. Sistem yang dibangun merupakan sistem yang mengadopsi metode Weighted Aggreated Sum Product Assesment (WASPAS) khususnya untuk mengatasi masalah dalam penentuan kindergarten teacher pada RA Umar Mirza.

\section{UCAPAN TERIMA KASIH}

Terimakasih diucapkan kepada Bapak Purwadi dan Bapak Ardianto Pranata yang telah membimbing dalam penyelesaian penelitian ini dan kepada pihak-pihak yang tidak dapat disebutkan satu persatu. Kiranya bisa memberi manfaat bagi pembaca dan dapat meningkatkan kualitas penelitian selanjutnya.

\section{REFERENSI}

[1] Muhammedi, "Peran Raudhtul Athfal (RA) dalam Membina Generasi Islam yang Berkarakter," raudhah, vol. V, no. 1, pp. 1-20, 2017.

[2] I. B. Maryatun, "Peran Pendidik Paud Dalam Membangun Karakter Anak," J. Pendidik. Anak, vol. 5, no. 1, pp. 747-752, 2016.

[3] L. Kristiyanti and A. Sugiharto, "Sistem Pendukung Keputusan Pemilihan Pengajar Les Privat Untuk Siswa Lembaga Bimbingan Belajar Dengan Metode Ahp,” J. Masayrakat Inform., vol. 4, no. 7, pp. 39-47, 2007.

[4] M. Handayani and N. Marpaung, "Implementasi Metode Weight Aggregated Sum Product Assesment (Waspas) Dalam Pemilihan Kepala Laboratorium," vol. 9986, no. September, pp. 253 - 258, 2018.

[5] J. Hutagalung, D. Nofriansyah, and M. A. Syahdian, "Penerimaan Bantuan Pangan Non Tunai ( BPNT ) Menggunakan Metode ARAS," vol. 6, no.1, pp. 198-207, 2022, doi: 10.30865/mib.v6i1.3478.

[6] J. Hutagalung and A. Azlan, "Pemanfaatan GIS dan AHP dalam Penerimaan Dana BOS Jenjang SMA,"JURTEKSI (Jurnal Teknologi dan Sistem Informasi), vol. VI, no. 3, pp. 221-230, 2020

[7] H. Winata and A. H. Nasyuha, "Sistem Pendukung Keputusan Untuk Menentuka Kelayakan Penerima Bantuan Siswa Miskin ( BSM ) Pada SD Negeri 8 Bintang Menggunakan Metode Technique for Order Preference by Similarity to Ideal Solution ( TOPSIS )," vol. 17, no. 2, pp. 198-205, 2018.

[8] A. F. Boy and D. Saripurna, "Sistem Pendukung Keputusan Dalam Menentukan Tingkat Kepuasan Pelanggan Terhadap Pelayanan di Toko Indomaret Menggunakan Metode Fuzzy Associative Memory ( FAM ),” vol. 3, no. 1, pp. 78-85, 2020. 
[9] B. Andika, M. Dahria, E. Siregar, A. Info, and S. P. Keputusan, "SISTEM PENDUKUNG KEPUTUSAN UNTUK MENENTUKAN LOKASI PEMBANGUNAN PERUMAHAN TYPE $36 \mathrm{M} / \mathrm{S}$ MENGGUNAKAN METODE WEIGHTED PRODUCT PADA PT . ROMEBY KASIH ABADI,” vol. 18, no. 2, pp. 130-138, 2019.

[10] I. Chairani, D. Nofriansyah, A. H. Nasyuha, and I. Mariami, "Implementasi metode waspas untuk menentukan ketua kemuslimahan pusat komunikasi daerah lembaga dakwah kampus sumut *," vol. 3, no. 2, pp. 25-33, 2020.

[11] P. S. Ramadhan and S. Yakub, "Sistem Pendukung Keputusan dalam Menenetukan Calon ( Tailor ) Penjahit di Ranhouse Medan dengan Menggunakan Metode AggregatedSum Product Assesment," vol. 3, no. 2, pp. 12-24, 2020.

[12] L. M. Laia, B. Andika, and E. F. Ginting, "Sistem Pendukung Keputusan Dalam Menentukan Lokasi Strategis Cabang Baru di UD . Ario Nias Selatan Menggunakan Metode WASPAS ( Weighted Aggregated Sum Product Assesment )," no. 4, 2021.

[13] A. Hidayathy, M. Syahril, U. Fatimah, and S. Sitorus, "E-Surveillance Dalam Penentuan Cabang Baru Pada Al Haramain Tour \& Travel dengan Menggunakan Metode WASPAS," vol. 3, no. 2, pp. 88-95, 2020.

[14] J. Karim, "Sistem Pendukung Keputusan Penentuan Prioritas Pembangunan Menggunakan Metode Promethee Pada Desa Ayula Kecamatan Randangan Kabupaten Pohuwato Provinsi Gorontalo,” ilmu Komput., vol. 10, no. April, pp. 86-91, 2018.

[15] J. Hutagalung and Mentari Tri Indah R,"Pemilihan Dosen Penguji Skripsi Menggunakan M. Aras and C. Waspas," vol. 10, no.3, pp. 354-367, 2021.

\section{BIOGRAFI PENULIS}

\begin{tabular}{|c|l|}
\hline Vivi Anggriani & \\
\hline Purwadi & $\begin{array}{l}\text { NIDN : 0104038004 } \\
\text { Program Studi : Manajemen Informatika } \\
\text { Deskripsi : Dosen Tetap STMIK Triguna Dharma yang aktif } \\
\text { mengajar dan fokus pada bidang keilmuan Desain, Pemrograman } \\
\text { Web, Komputer Teknik. } \\
\text { Prestasi : Dosen Terbaik STMIK Triguna Dharma Tahun } 2017\end{array}$ \\
\hline \multirow{3}{*}{ Ardianto Pranata } & $\begin{array}{l}\text { NIDN : 0112029101 } \\
\text { Program Studi : Sistem Komputer } \\
\text { Deskripsi : Dosen Tetap STMIK Triguna Dharma yang aktif } \\
\text { mengajar dan fokus pada bidang keilmuan } \\
\text { Mikrokontroler, Komputer Desain dan Sistem Kendali. Telah } \\
\text { menulis artikel jurnal berjudul "Automatic Scroll saw System } \\
\text { dengan Teknik Kendali kecepatan PWM berbasis Arduino", } \\
\text { serta beberapa judul lain terkait sistem kendali otomatis. } \\
\text { Menjabat sebagai Ketua Program Studi Sistem Komputer sejak } \\
\text { Januari 2021 }\end{array}$ \\
\hline
\end{tabular}

